\title{
DISSEMINAÇÃO DA CULTURA DO DESEMPENHO NA EDUCAÇÃO BÁSICA BRASILEIRA: a atuação do Governo Federal (1995-2012)
}

\author{
Patrícia Rocha de Brito Lira ${ }^{1}$ \\ Andréia Ferreira da Silva²
}

\section{RESUMO}

O artigo apresenta resultados de pesquisa que examinou a atuação do Governo Federal na disseminação da cultura do desempenho na educação básica brasileira no período de 1995 a 2012. A cultura do desempenho compreende uma pluralidade de princípios, conhecimentos, valores, tecnologias e modos de fazer, de pensar e de se comportar fundadas no desempenho. Delega ao mercado a elaboração de modelos gestores educacionais (técnicos) e responsabiliza a escola pelos resultados (NOSELLA; BUFFA; LEAL, 2010). O fortalecimento dessa cultura vem gerando alterações significativas no cotidiano educativo. O texto examina quatro estratégias do Governo Federal que objetivaram a disseminação e o fortalecimento da cultura do desempenho na educação brasileira: a) a instituição de um sistema de avaliação da educação básica b) a realização de olimpíadas científicas em diferentes áreas do conhecimento c) a concessão de premiação a "iniciativas exitosas" de docentes e escolas e d) a implantação de ações para a mobilização social para o acompanhamento e fiscalização da qualidade da educação. 0 texto resulta de revisão da literatura que analisa as políticas de avaliação externa no país e da análise de documentos legais e normativos federais. A investigação revela o caráter de continuidade das iniciativas instituídas pelo Governo Federal no período estudado, marcado pelo aprofundamento da lógica gerencial, pela disseminação dos valores de mercado no campo educacional público e pela indução dos governos estaduais e municipais à criação de seus sistemas próprios de avaliação e ao uso de seus resultados com fortes consequências para os docentes.

Palavras-chave: Cultura do desempenho. Políticas de avaliação da educação básica. Atuação do Governo Federal.

\footnotetext{
1 Mestre em Educação pela Universidade Federal da Paraíba. Docente Educação Básica da Prefeitura Municipal de Campina Grande. E-mail: patriciablira@hotmail.com

2 Doutora em Educação pela Universidade Federal Fluminense. Professora da Universidade Federal de Campina Grande. E-mail: silvaandreia@uol.com.br
} 


\title{
DISSEMINATION OF CULTURE OF PERFORMANCE IN BRAZILIAN BASIC EDUCATION: the Federal Government's activities (1995-2012)
}

\begin{abstract}
This article presents research results that examined the performance of the Federal Government in the dissemination of performance culture in Brazilian basic education from 1995 to 2012. The performance culture comprises a plurality of principles, knowledge, values, technologies and modes of performance do, think and behave based on performance. It delegates to the market the elaboration of educational (technical) managers models and makes the school responsible for the results (NOSELLA; BUFFA; LEAL, 2010). The strengthening of this culture has generated significant changes in the educational daily. The text examines four strategies of the Federal Government that aimed to disseminate and strengthen the culture of performance in Brazilian education: a) the establishment of a system of assessment of basic education b) the holding of scientific olympiads in different areas of knowledge c) the awarding of prizes to "successful initiatives" of teachers and schools; and d) the implementation of actions for social mobilization to monitor and supervise the quality of education. The text results from a review of the literature that analyzes the policies of external assessment in the country and the analysis of legal and normative federal documents. The research reveals the continuity of the initiatives instituted by the Federal Government in the period studied, marked by the deepening of managerial logic, by the dissemination of market values in the public educational field and by the induction of state and municipal governments to create their own evaluation systems and the use of its results with strong consequences for teachers.
\end{abstract}

Keywords: Performance culture. Policies for the assessment of basic education. Performance of the Federal Government.

\section{DISEMINACIÓN DE LA CULTURA DEL DESEMPEÑO EN LA EDUCACIÓN BÁSICA}

BRASILEÑA: la actuación del Gobierno Federal (1995-2012)

\section{RESUMEN}

El artículo presenta resultados de investigación que examinó la actuación del Gobierno Federal en la diseminación de la cultura del desempeño en la educación básica brasileña en el período de 1995 a 2012. La cultura del desempeño comprende una pluralidad de principios, conocimientos, valores, tecnologías y modos de vida, de hacer, de pensar y de comportarse fundadas en el funcionamiento del mercado, la elaboración de modelos gestores educativos (técnicos) y responsabiliza a la escuela por los resultados (NOSELLA; BUFFA; LEAL, 2010). El fortalecimiento de esa cultura viene generando cambios significativos en el espacio educativo. El texto examina cuatro estrategias del Gobierno Federal que objetivaron la diseminación y el fortalecimiento de la cultura del desempeño en la educación brasileña: a) la institución de un sistema de evaluación de la educación básica b) la realización de olimpiadas científicas en diferentes áreas del 
conocimiento c) la concesión de premios a "iniciativas exitosas" de docentes y escuelas y d) la implantación de acciones para la movilización social para el seguimiento y fiscalización de la calidad de la educación. El texto es resultado de una revisión de la literatura que analiza las políticas de evaluación externa en el país y del análisis de documentos legales y normativos federales. La investigación revela el carácter de continuidad de las iniciativas instituidas por el Gobierno Federal en el período estudiado, marcado por la profundización de la lógica gerencial, por la diseminación de los valores de mercado en el campo educativo público y por la inducción de los gobiernos estatales y municipales a la creación de sus propios sistemas de evaluación y el uso de sus resultados con fuertes consecuencias para los docentes.

Palabras clave: Cultura del rendimiento. Políticas de evaluación de la educación básica. La actuación del Gobierno Federal.

\section{INTRODUÇÃO}

O presente artigo analisa a atuação do governo federal no processo de implantação e aprofundamento da cultura do desempenho na educação básica brasileira no período de 1995 a 2012, pautada nos princípios da responsabilização, da meritocracia, da competição e do individualismo como valor moral radical. O trabalho foi desenvolvido tendo como fonte a realização de pesquisa bibliográfica sobre as políticas adotadas pelo Governo Federal para viabilizar a disseminação e a implantação de uma cultura de avaliação e de desempenho na educação básica brasileira e a análise de documentos legais e normativos federais do setor educacional.

O artigo discute, inicialmente, a emergência da cultura do desempenho nos países de capitalismo central, a partir da década de 1980, buscando analisar sua origem, fundamentos e conceito, bem como situar sua emergência no campo da educação. Em seguida, analisa o processo de disseminação da cultura do desempenho na educação básica brasileira no âmbito das políticas federais, de 1995 a 2012, por meio de mecanismos de avaliação externa padronizada e das iniciativas de premiação, e de punição, que estimulam a competição, a responsabilização ${ }^{3}$ dos profissionais

\footnotetext{
3 Ravela (2003) analisa o uso previsto dos resultados das avaliações em países da América Latina e identifica duas tendências denominadas de baixo risco ou "low stakes" e alto risco ou "high stakes". O autor explica que o uso dos resultados de tais exames considerados de
} 
e das escolas pelos desempenhos dos estudantes: a) a instituição de um sistema de avaliação da educação básica b) a realização de olimpíadas científicas em diferentes áreas do conhecimento c) a concessão de premiação a "iniciativas exitosas" de docentes e escolas e d) a implantação de ações para a mobilização social para o acompanhamento e fiscalização da qualidade da educação.

\section{CULTURA DO DESEMPENHO NA EDUCAÇÃO BÁSICA}

Para reconhecer $O$ processo de constituição da cultura do desempenho e sua emergência no campo educacional se faz necessário relacioná-lo às transformações econômicas, políticas, sociais e ideológicas impulsionadas pela crise do sistema capitalista, a partir da segunda metade da década de 1970. Essa crise, que se instalou em países centrais e periféricos do capitalismo, fez emergir processos de reestruturação produtiva e de fortalecimento da ideologia neoliberal que, resultou em processos de reforma do Estado e no fortalecimento dos princípios gerenciais no setor público. Tais processos demandaram, na lógica do capital, mudanças profundas no papel do Estado, que repercutiram significativamente na definição das políticas sociais no contexto mundial. No setor educacional, tais mudanças passaram a requerer a utilização de critérios de eficiência e eficácia de acordo com os interesses de mercado, visando a constituição de "quase-mercados" na educação.

Nesse contexto, um dos eixos principais do processo de implantação da reforma educacional consistiu nas políticas de avaliação externa, como parte constitutiva da reforma do Estado e da adequação da educação às

baixo risco é caracterizado por "avaliações cujos resultados têm função unicamente informativa e formativa, mas não preveem consequências" (RAVELA, 2003, p. 7). Enquanto que, o uso dos resultados das avaliações classificado de alto risco, de acordo com o Ravela (2003), caracteriza as "avaliações cujos resultados terão consequências diretas aos indivíduos ou instituições e, por conseguinte, implicam um certo nível de risco ou ameaça, porque implicam algum tipo de sanção positiva ou negativa" (RAVELA, 2003, p. 7).

${ }^{4}$ Segundo Santos (2004), "o termo 'quase-mercado' constitui-se uma expressão que busca definir a introdução de atuação do mercado e do setor privado na implementação de políticas de bem-estar e na oferta da educação (p. 1146-1147, destaque do original). 
novas demandas do capital, às premissas do neoliberalismo de Terceira Via ${ }^{5}$ e aos princípios do gerencialismo. Tal modelo de avaliação, segundo Sousa (2009), tem se constituído como instrumento privilegiado para a inserção de valores e formas de organização do mercado no setor educacional. Como resultado, para Ball (2002; 2004; 2005; 2010), vem sendo construída uma nova ambiência no campo educacional com novas identidades, novas formas de interação, novas linguagens, novos sistemas éticos, novos valores e novas rotinas nas escolas.

De acordo com Ball (2002; 2005), os elementos-chave da reforma educacional em curso desde o final do século XX, que abrange da educação básica à pós-graduação, são o mercado, a capacidade de gestão (gerencial) e a performatividade. Essas tecnologias, quando aplicadas em conjunto, oferecem uma alternativa politicamente atrativa e eficaz às velhas tecnologias do profissionalismo e da burocracia, visto que formam uma nova ambiência, na qual os órgãos de gerenciamento central assumem novos papéis, com base em duas vertentes: os "sistemas de monitoramento" e a "produção de informações", buscando estabelecer mudanças de comportamento de todos os lados (BALL, 2002).

O gerencialismo, segundo Ball (2005), "desempenha o importante papel de destruir os sistemas ético-profissionais que prevaleciam nas escolas, provocando sua substituição por sistemas empresariais competitivos" (BALL, 2005, p. 544-545), gerando mudanças na identidade docente, com a constituição de novas subjetividades profissionais, novos sentidos e identidades. Procura incutir a performatividade na alma do trabalhador e criar um ambiente adequado para o desenvolvimento da cultura da performatividade no espaço educativo. A performatividade, por sua vez, consiste em

\footnotetext{
5 A Terceira Via resulta de um movimento revisionista do modelo neoliberal ortodoxo, com a proposta de, segundo Martins (2009), "buscar um realinhamento do projeto neoliberal de tal modo que o crescimento da economia fosse recuperado, como postulava a ortodoxia, mas em bases políticas mais sustentáveis que não gerassem tanta resistência e abalo na coesão social dos países" (p. 60).
} 
uma tecnologia, uma cultura e um modo de regulação que se serve de críticas, comparações e exposições como meios de controle, atrito e mudança. Os desempenhos (de sujeitos individuais ou organizações) servem como medidas de produtividade e rendimento, ou mostras de 'qualidade' ou ainda 'momentos' de promoção e inspeção. Significam, englobam e representam a realidade, a qualidade ou valor de um indivíduo ou organização dentro de um determinado âmbito de julgamento e avaliação (BALL, 2002, p. 4).

Na cultura da performatividade, a busca pelo desempenho máximo e pela excelência é uma constante (BALL, 2002). Nesse sentido, o profissional é reduzido à obediência às regras e à satisfação de desempenhos fixos e impostos externamente. No âmbito educacional, o professor, é concebido simplesmente como o profissional que "produz desempenhos" (BALL, 2005), isso implica que, "os professores perderam a possibilidade de exigir respeito, exceto em termos de desempenho" (BALL, 2002, p. 543).

A expressão cultura da performatividade e, no geral, os valores que a constituem, apresentados por Ball (2002; 2004; 2005; 2010), vêm sendo designados por diferentes autores como: cultura empresarial (LIMA, 2002), cultura de resultados (SHIROMA et al, 2008), Cultura de auditoria (FREITAS, 2011; 2013a) e cultura da avaliação (FREITAS, 2013a; 2013b). No presente estudo, é utilizada a denominação cultura do desempenho, termo empregado pelos pesquisadores brasileiros Santos (2004) e Nosella (2010).

De acordo com Santos (2004), a cultura de desempenho "desenvolve uma nova atmosfera de trabalho, [...] a qual vai redefinindo as formas de trabalho e as relações dos docentes com as suas atividades cotidianas" (p. 1146). Para a autora, "esse processo se baseia em três princípios operacionais: economia, eficácia e eficiência" (SANTOS, 2004, p. 209). A adoção desses princípios denuncia uma visão utilitarista da educação que se opõe a uma proposta de formação para o exercício pleno da cidadania, com ênfase na criação e/ou consolidação de uma real democracia (SANTOS, 2004).

Nosella (2010) conceitua cultura do desempenho, na política educacional, como "a cultura explícita do mercado, que apresenta um 
conjunto de modelos estandardizados, consolidados e impostos aos educadores" (p. 37). Nessa cultura, o ato de educar torna-se fundamentalmente uma dimensão técnica ou mecânica, visto que essa cultura "mede resultados, estabelece estratégias, fixa metas e estimula a produção, entretanto, não percebe o real da educação" (NOSELLA, 2010, p. $50)$.

É importante indicar que os referidos autores se utilizam do termo cultura para referir-se às mudanças nos valores e nas concepções que norteiam o trabalho escolar, mas que, também, alcançam a sociedade mais ampla. Desse modo, pode-se afirmar que a cultura do desempenho educacional envolve a construção, nas escolas e nos sistemas de ensino, de rotinas, ações, linguagens, modos de ser e de pensar pautados em valores da competição, da concorrência, do individualismo e da meritocracia. O fortalecimento desses valores contribui para a manutenção e legitimação da forma de organização societária capitalista. Nesse contexto, a educação torna-se um importante instrumento no processo de naturalização e sedimentação dos valores e princípios dominantes na sociedade contemporânea, uma vez que, de acordo com Martins e Neves (2013), a "educação é parte inerente da instituição da cultura" (p. 345). Trata-se de um esforço de naturalizar e moldar novas subjetividades nos espaços educativo e social às demandas da sociabilidade burguesa em contextos de crise e incertezas.

A implantação do modelo gerencial de administração - nova gestão pública, no setor educacional, tem levado à adoção de medidas de racionalização, visando maior eficiência, eficácia e foco no desempenho, envolvendo a utilização de políticas de avaliação e de responsabilização dos gestores e docentes. Nessa perspectiva, a avaliação torna-se um instrumento que permite o desenvolvimento e a aplicação das categorias e princípios nos quais se assentam a cultura do desempenho educacional.

Esse modo de organização do sistema educacional, que passa a ter como referência de gestão a organização empresarial, permite o retorno de 
abordagens tecnocráticas. De acordo com Freitas (2012), a partir da década de 1990, o neotecnicismo passa a ser dominante nas políticas educacionais, estruturado em torno de três categorias: a responsabilização, a meritocracia e a privatização. Essas três categorias constituem a base do que está sendo denominado, nesse estudo, de cultura do desempenho.

A primeira categoria, a responsabilização, é referida por Freitas (2012; 2016) como um sistema de responsabilização composto por três elementos: testes para estudantes, divulgação pública do desempenho da escola e recompensas e sanções. Para o bom funcionamento desse sistema, além de um sistema de avaliação em larga escala, é necessária uma



Freitas (2016) explica que as recompensas e sanções, em conjunto com a divulgação pública dos resultados da escola, compõem o caráter meritocrático do sistema de responsabilização. Dessa maneira, a meritocracia é uma categoria que perpassa a responsabilização. A meritocracia está na base da proposta política liberal: igualdade de oportunidade e não de resultados, pois, a diferença estaria entre as pessoas e no seu esforço pessoal.

A terceira categoria central do neotecnicismo consiste na privatização da educação. De acordo com Freitas $(2012 ; 2016)$, a responsabilização e a meritocracia criam a ambiência adequada para a ampliação da privatização do sistema público educacional. O conceito de privatização sofreu mudanças nas últimas décadas. Para este autor, com a introdução das noções de público estatal e público não estatal, a linha divisória entre o público e o privado ficou cada vez mais tênue e abriu novas perspectivas para o empresariado. Atualmente, os processos de privatização na educação estão avançando da seguinte forma: 
privatização por terceirização de gestão, quando essa passa a ser exercida por uma organização social privada; terceirização por deslocamento de recursos públicos diretamente para os pais na forma de vouchers que utilizam para 'escolher' em qual escola particular devem matricular seus filhos; e também privatização por introdução no interior da escola de lógicas de gestão privadas e sistemas de ensino pré-fabricados (em papel ou na forma de software) (FREITAS, 2016, p. 141).

Freitas (2016) destaca ainda que, a privatização é o destino final dessa política reformista e que a responsabilização e a meritocracia produzem as razões que levariam ao imperativo da privatização.

As categorias constitutivas do neotecnicismo, apresentadas por Freitas (2012), têm tornado-se cada vez mais presentes no campo educacional, inaugurando uma nova fase das políticas educacionais, com a associação de incentivo ou sanções aos resultados nas avaliações externas. Nesse contexto, a disseminação da cultura do desempenho na escola, e na sociedade em geral, vem contribuindo para a naturalização das desigualdades sociais e educacionais, para o fortalecimento dos princípios da competividade e da meritocracia e para o esvaziamento de uma proposta crítica de formação na escola.

\section{Estratégias adotadas pelo Governo Federal na disseminação da cultura do desempenho (1995-2012)}

O governo federal brasileiro formulou, implantou e apoiou iniciativas e programas, no período de 1995 a 2012, que possibilitaram a disseminação da cultura do desempenho na educação básica brasileira. Foram identificadas, no presente estudo, quatro principais estratégias: a) a instituição de um sistema de avaliação da educação básica no país, que consiste na mais importante, orgânica e eficiente dessas estratégias b) a realização de olimpíadas científicas em diferentes áreas do conhecimento c) a concessão de premiação a "práticas exitosas" de docentes e escolas e d) a implantação de ações para a mobilização social para o acompanhamento e fiscalização da qualidade da educação. A seguir, são apresentadas e analisadas essas estratégias. 


\section{Sistema de avaliação da educação básica}

A primeira iniciativa, apresentada nesse artigo, que vem colaborando para a difusão, no país, dos valores constitutivos da cultura do desempenho no campo educacional e na sociedade como um todo, consiste na implantação de um sistema de avaliação educação básica. Essa consiste na iniciativa do Governo Federal mais articulada, duradoura e que sendo aprofundada, nos últimos anos, com a instituição de mecanismos de indução para sua assimilação pelos governos estaduais e municipais.

A partir dos anos 1990, vem se constituindo no país um novo modelo de regulação do Estado, concretizando a implantação do Estado regulador e avaliador. De acordo com Afonso (2009), O Estado, no campo educacional,

vem adotando um ethos competitivo, neodarwinista, passando a admitir a lógica de mercado, através da importação para o domínio público de modelos de gestão privada, com ênfase nos resultados ou produtos dos sistemas educativos" (p. 49).

Sousa (2009) destaca a atuação do Estado regulador e avaliador como estimulador da produção de uma educação de "qualidade diferenciada" mediante a instituição de mecanismos de sua medição, da publicização dos resultados e do estímulo à competição entre os envolvidos. Nesse modelo de regulação estatal, as políticas de avaliação externa, direcionadas à educação, básica ganharam destaque como estratégias centrais para a melhoria da qualidade da educação, compreendida como elevação dos desempenhos dos estudantes nos testes padronizados.

De acordo com Bonamino e Sousa (2012), o sistema de avaliação externa da educação implantado no país, desde os anos finais da década de 1980, passou por três gerações dos usos de seus resultados. A primeira geração vincula-se à criação do Sistema de Avaliação da Educação Básica (SAEB), no ano de 1988. Nessa geração, foi enfatizado o uso dos resultados dos testes com caráter diagnóstico e amostral, não possuindo função de 
atribuir consequências diretas para a escola e para o currículo (BONAMINO; SOUSA, 2012).

A avaliação de segunda geração, foi implantada com a criação da Prova Brasil, em 2005, quando da reformulação do SAEB, e deu início às políticas de responsabilização branda. Segundo Bonamino e Sousa (2012), a novidade em relação à geração anterior é que os resultados passaram a ser divulgados por escolas, permitindo, dessa maneira, a apropriação dessas informações pelos pais e pela sociedade. Nesse tipo de mecanismo de responsabilização, as consequências são apenas simbólicas, do tipo baixo risco ou low stakes, e têm "como pressuposto que o conhecimento dos resultados favorece a mobilização das equipes escolares para a melhoria da educação" (BONAMINO; SOUZA, 2012, p. 375).

A partir de 2007, visando à consolidação do modelo de avaliação em curso, foram instituídos o Plano de Metas Compromisso Todos pela Educação, objeto do Decreto n. 6.094, de 24 de abril de 2007, o IDEB e o Plano de Ações Articuladas (PAR), ações constitutivas do Plano de Desenvolvimento da Educação (PDE), lançado em 2007.

Com o estabelecimento do IDEB, definido pelo Governo Federal como um indicador objetivo da qualidade da educação no país, deu-se um passo importante para a intensificação da perspectiva da responsabilização e a instituição do uso dos resultados da avaliação de segunda geração. O estabelecimento de um índice nacional para medir a qualidade da educação, articulado à construção de rankings, com base nos desempenhos nos testes padronizados, e a ampla divulgação desses resultados gerou um forte impacto nas relações estabelecidas entre os docentes, os gestores, as escolas, os sistemas de ensino e a sociedade como um todo. Nesse sentido, O IDEB tornou-se uma iniciativa importante no fortalecimento da cultura do desempenho na educação brasileira, ao estabelecer metas a serem alcançadas por cada escola até o ano de 2021, com a previsão de estratégias de monitoramento para sua elevação, inclusive comparando com os resultados de outros países. 
Outra iniciativa de destaque no PDE é o Plano de Metas Compromisso Todos pela Educação, que contribui significativamente para o fortalecimento da atuação da União, no âmbito educacional subnacional, instituindo, segundo Freitas (2007), um regime de colaboração sob condicionalidades. Com o Plano de Metas, o Governo Federal instituiu mecanismo de indução dos estados e municípios para a implantação de diretrizes centralmente formuladas visando a elevação do IDEB e os alcance das metas propostas (SILVA, 2010). Desde o lançamento do PDE, em 2007, as transferências voluntárias e de assistência técnica do MEC estão condicionadas à adesão ao Plano de Metas Compromisso Todos pela Educação, tendo como referência as metas do IDEB e a elaboração do PAR6.

A terceira geração dos usos dos resultados das avaliações de são indicativas consiste na implantação de mecanismos de responsabilização com consequências fortes ou high stakes, "contemplando sanções ou recompensas em decorrência dos resultados de alunos e escolas" (BONAMINO; SOUZA, 2012, p. 375). Esta geração se funda nos país com a criação de sistemas municipais e estaduais de avaliação da educação básica que instituem o pagamento de premiação e bonificação "por mérito", de acordo com os resultados obtidos nas avaliações. A ampliação das iniciativas de avaliação de terceira geração vem contribuindo para o aprofundamento da cultura do desempenho na educação básica brasileira, com a crescente preocupação, nas escolas e sistemas de ensino, com o alcance dos desempenhos previstos.

Segundo Santos (2013), essa política de avaliação

está ancorada em elementos como o ranqueamento e a premiação. São elementos que exercem forte atração, uma vez que trabalham com alguns sentimentos humanos que estão muito explorados, atualmente, na sociedade de consumo [...]. São

\footnotetext{
${ }^{6}$ Nesse contexto, segundo Schneider, Nardi e Durli (2012), o Plano de Ações Articuladas (PAR) consiste na principal política de indução e de regulação das ações do PDE nos estados e municípios, pois é mediante a realização das suas diretrizes, ações e programas que são materializadas as metas do PDE/Plano de Metas.
} 
sentimentos que exploram a competição, a concorrência, a inveja, a cobiça, a vaidade e a culpa pelo fracasso (p. 230).

Esses valores vêm sendo reforçados pelas políticas contemporâneas de avaliação externa da educação, contribuindo na difusão e na legitimação, no âmbito educacional, de uma formação que ratifica a dinâmica da sociedade capitalista. Neste contexto, as relações no interior da escola sofrem modificações e "as pessoas passam a ser vistas apenas pelo prisma da produtividade" (SANTOS, 2013, p. 240).

\section{Realização das olimpíadas científicas por áreas de conhecimento}

A segunda iniciativa apoiada e realizada pelo Governo Federal que vem contribuindo para a difusão da cultura do desempenho na educação básica no país consiste na realização de olimpíadas científicas em diferentes áreas do conhecimento.

Desde a década de 1990, em maior número, vêm ocorrendo no país, anvalmente, as olimpíadas do conhecimento, que são organizadas por entidades das áreas científicas. Tais olimpíadas são competições direcionadas a estudantes do ensino fundamental e médio. Foram identificadas, nesse estudo, no período de 1995 a 2012, dois tipos de olimpíadas científicas: as criadas pelas entidades científicas, que já existiam no país desde o final dos anos 1970, e as criadas pelo governo federal. É importante registrar que as associações científicas, muitas vezes, contam com o apoio do Governo Federal na realização destes eventos. A seguir são apresentadas as principais olimpíadas realizadas no país, no período investigado, e suas características centrais, tendo como referência estudo realizado por Lira (2013).

A Olimpíada Brasileira de Matemática (OBM) vem sendo organizada, desde 1979, pela Sociedade Brasileira de Matemática (SBM), com apoio do Conselho Nacional de Desenvolvimento Científico e Tecnológico (CNPq). Participam deste evento estudantes brasileiros do $6^{\circ}$ ano do Ensino Fundamental até estudantes universitários de instituições públicas ou 
privadas. A Olimpíada Brasileira de Química (OBQ), criada, em 1986, por iniciativa do Instituto de Química da Universidade de São Paulo (USP). Após ter sua realização suspensa, voltou a acontecer, em 1996, por iniciativa da Universidade Federal do Ceará (UFC), da Universidade Estadual do Ceará (UECE) e da Fundação Cearense de Apoio ao Desenvolvimento Científico e Tecnológico (FUNCAP), com o patrocínio da Petrobrás e da Editora Saraiva. A OBQ recebe o apoio do $C N P q$, da Associação Brasileira da Indústria de Álcalis, Cloro e Derivados (ABICLOR) e da Associação Brasileira da Indústria Química (ABIQUIM). Participam dessa competição estudantes do Ensino Médio das escolas públicas e privadas que tenham disputado as olimpíadas estaduais de química (LIRA, 2013).

A Olimpíada Brasileira de Informática (OBI) foi criada em 1999, sendo organizada pelo Instituto de Computação da UNICAMP e realizada pela Sociedade Brasileira de Computação (SBC). A competição é voltada para alunos do Ensino Fundamental e Médio selecionados em diferentes modalidades, de acordo com o nível de escolaridade. Também criada em 1999, a Olimpíada Brasileira de Física, que é um programa permanente da Sociedade Brasileira de Física (SBF) com o apoio do CNPq. Esse programa é destinado aos estudantes do Ensino Médio (LIRA, 2013).

A Fundação Oswaldo Cruz, em parceria com a Associação Brasileira de Saúde Coletiva (ABRASCO), em 2001, criou a Olimpíada Brasileira do Meio Ambiente (OBSMA). Realizada a cada dois anos, a OBSMA recebe, avalia e divulga projetos de alunos e professores do $6^{\circ}$ e $9^{\circ}$ ano do Ensino Fundamental e do $1^{\circ}$ e $4^{\circ}$ ano do Ensino profissionalizante e da Educação de Jovens e Adultos (EJA). A Olimpíada do Conhecimento é uma competição da educação profissional, criada em 2001. É promovida pelo Serviço Nacional de Aprendizagem Industrial (SENAI) e destinada a estudantes do SENAI selecionados e que passam por seleção na escola e no estado (LIRA, 2013).

Em 2005, foi criada pela Associação Nacional de Biossegurança (ANBio) a Olimpíada Brasileira de Biologia (OBB), destinada à participação 
de estudantes do nível médio (OBB, 2013). Em 2006, destaca-se a criação da Olimpíada Nacional de Oceanografia (ONO), aprovada pelo CNPq, sendo uma iniciativa conjunta da Associação Brasileira de Oceanografia (AOCEANO) e do Fórum de Coordenadores de Cursos de Graduação em Oceanografia do Brasil. A competição é voltada para estudantes do $8^{\circ}$ e $9^{\circ}$ ano do Ensino Fundamental e alunos do Ensino Médio e que não estejam matriculados em nenhuma instituição de Ensino Superior até o dia da prova. Nesse contexto, merece destaque a criação direta, por parte do governo federal, de uma olimpíada científica destinada para as escolas públicas, a Olimpíada Brasileira de Matemática das Escolas Públicas (OBMEP). A OBMEP foi criada em 2005, promovida pelo MEC, em parceria com o Instituto Nacional de Matemática Pura e Aplicada (IMPE), e é dirigida a alunos do sexto ao nono ano do Ensino Fundamental e aos alunos do Ensino Médio (LIRA, 2013).

Na OBMEP, as premiações vão além da distribuição de medalhas e certificados, a exemplo da distribuição de bolsas de iniciação científica com edital específico do CNPq. Essa competição possui as seguintes realizações: - Programa de Iniciação Científica Jr. (PIC), para os medalhistas estudarem Matemática por 1 ano, com bolsa CNPq; o Programa de Iniciação Científica - Mestrado (PICME), para medalhistas que estejam cursando graduação com bolsas do CNPq (IC) e CAPES (Mestrado); a Preparação Especial para Competições Internacionais (PECI), que prepara medalhistas de ouro selecionados pela excepcionalidade de seus talentos para competições internacionais; O POTI - Polos Olímpicos de Treinamento Intensivo, que pretende democratizar e ampliar o acesso dos alunos brasileiros a treinamento para competições matemáticas; a criação dos Clubes de Matemática, que vão propiciar outros modos de estudo da matemática entre alunos e professores, com atividades interessantes e em ambiente interativo; a mobilização de Coordenadores Regionais para a realização de atividades como seminários com professores e cerimônias de premiação (LIRA, 2013). 
De maneira geral, de acordo com Lira (2013), essas competições possuem os seguintes objetivos: melhorar e avaliar a qualidade do ensino; selecionar jovens para representar o Brasil nas competições internacionais; incentivar a dedicação dos estudantes; identificar os melhores estudantes e incentivar os jovens para se tornarem futuros profissionais.

Essas competições, segundo Lira (2013), apresentam semelhanças em suas formas de realização. As competições nacionais são precedidas por etapas estaduais em que são selecionados os alunos que participarão dos eventos nacionais. Estes, por sua vez, selecionam os que representarão o Brasil em competições internacionais nas respectivas áreas de conhecimento. No nível nacional, a realização das competições, na maioria das vezes, é dividida em três etapas e em níveis de acordo com a escolarização dos estudantes (LIRA, 2013).

No que se refere à concessão de premiações aos competidores com os melhores resultados, na cerimônia de premiação, os estudantes, a depender de suas colocações, recebem medalhas de ouro, prata e bronze. Há, também, a entrega de certificados para todos os alunos participantes e para a escola. Em várias situações, ocorre, também, a entrega de brindes relacionados à área de conhecimento da olimpíada (LIRA, 2013).

Apesar das olimpíadas, no Brasil, já serem realizadas desde a década de 1970, vinculadas às sociedades científicas e às universidades, a partir dos anos 2000, cumpre destacar o papel preponderante do governo federal no apoio financeiro para sua realização. Desde 2002, essas olimpíadas recebem suporte financeiro do CNPq. De acordo com o CNPq, o objetivo é apoiar a realização, em todo o território nacional, de Olimpíadas como um instrumento para a melhoria dos ensinos fundamental e médio, com a consequente atualização de professores, bem como de identificação de jovens talentosos que podem ser estimulados a seguir carreiras científicotecnológicas (BRASIL, MCT/CNPq, 2002).

Considerando as características usualmente presentes nos procedimentos de seleção e classificação adotados nessas competições, 
destaca-se a noção de meritocracia, pois fica subentendida a ideia de que o sucesso dos ganhadores resulta do esforço pessoal de professores e alunos, assim como os competidores que fracassam são responsabilizados pelos resultados negativos, visto que tiveram as mesmas oportunidades que os outros (REZENDE; OSTERMANN, 2012).

Também devem ser considerados os regulamentos dessas competições, pois estabelecem e definem os conteúdos a serem estudados, contribuindo para a definição do currículo das disciplinas e a priorização de determinados saberes. Sobre a preparação dos alunos, segundo Lira (2013), com o objetivo de alcançar posições de destaque na competição, os alunos acabam sendo treinados para as provas. Essa prática, segundo Bonamino e Sousa (2012), já é conhecida com relação à avaliação em larga escala: o ensinar para o teste, prática que, no entendimento desse estudo, também se repete no que diz respeito às olimpíadas. Segundo as autoras, "os professores concentram seus esforços preferencialmente nos tópicos que são avaliados e desconsideram aspectos importantes do currículo" (BONAMINO; SOUSA, 2012, p. 383).

No Brasil, as olimpíadas científicas, em sintonia com elementos essenciais da cultura do desempenho, vêm contribuindo para a disseminação dos valores da competitividade, da meritocracia e do individualismo como princípios a serem adotados na formação humana e que, de maneira geral, implicam a autorresponsabilização do indivíduo pelo resultado do seu sucesso ou fracasso, assim como ocorre nas avaliações em larga escala, desconsiderando as condições sociais e econômicas.

\section{Premiação de "práticas exitosas" de escolas e docentes}

A terceira iniciativa do Governo Federal, como apoiador ou realizador, que vem contribuindo para a difusão da cultura do desempenho na educação básica no país consiste na concessão de prêmios a pessoas ou instituições que realizam "práticas exitosas" no campo da educação. 
Tais iniciativas de premiação dizem respeito à oferta de recompensas simbólicas, materiais e financeiras a pessoas, entidades e/ou professores de escolas públicas que desenvolveram práticas bem avaliadas pela instância organizadora do evento. Como exemplo destas iniciativas destacam-se o Prêmio Darcy Ribeiro de Educação e o Prêmio Professores do Brasil.

No ano de 1998, a Câmara dos Deputados criou o Prêmio Darcy Ribeiro de Educação, instituído pela Resolução n. 30, de 11 de agosto. $O$ Prêmio deve ser concedido, anualmente, a três pessoas e/ou entidades cujos trabalhos ou ações destacaram-se na defesa e na promoção da educação no Brasil. A Câmara dos Deputados confere diploma de menção honrosa e outorga medalha com a efígie de Darcy Ribeiro a três pessoas físicas ou jurídicas, escolhidas pela Comissão de Educação dentre aquelas indicadas por qualquer deputado ou senador. A cerimônia de outorga do Prêmio Darcy Ribeiro de Educação ocorre no Salão Nobre da Câmara dos Deputados, o que confere grande formalidade e pompa ao evento. A primeira edição do prêmio ocorrev em 2000 e, desde então, entre os mais agraciados com o prêmio estão fundações, institutos, entidades e redes de televisão, demonstrando a notável presença do empresariado na educação.

O Prêmio Professores do Brasil foi criado pelo Ministério da Educação, por meio da Secretaria de Educação Básica (SEB), em 2005, com o objetivo de reconhecer o mérito de professores das redes públicas de ensino pela contribuição dada para a melhoria da qualidade da educação básica, por meio de experiências pedagógicas bem-sucedidas, criativas e inovadoras. Objetiva, também, dar visibilidade às experiências pedagógicas conduzidas pelos professores, consideradas exitosas e que sejam passíveis de adoção por outros professores e pelos sistemas de ensino.

Para concorrer ao prêmio, os professores de escolas públicas da educação básica devem se inscrever, enviando um relato de prática pedagógica desenvolvida com seus alunos. Há um Comitê Nacional de Avaliação que analisa todos os relatos. O relato é avaliado e pode ser 
selecionado para receber uma premiação no nível estadual, regional e nacional.

Desde a criação dessa premiação docente, O MEC tem como instituições parceiras a Fundação SM, O Instituto Votorantim, a Associação Brasileira de Editores de Livros Escolares (Abrelivros), a Fundação Volkswagen, - Conselho Nacional dos Secretários de Educação (CONSED), a União Nacional dos Dirigentes Municipais de Educação (UNDIME), a Organização das Nações Unidas para a Educação, a Ciência e a Cultura UNESCO, a Organização dos Estados Ibero-Americanos para a Educação, a Ciência e a Cultura (OEI) e a Coordenação de Aperfeiçoamento de Pessoal de Nível Superior (LIRA, 2013). As empresas privadas são os responsáveis pelo pagamento da premiação em dinheiro, troféu e certificados aos docentes contemplados.

As iniciativas de premiação analisadas pautam-se em princípios propostos pela cultura do desempenho, considerando o estímulo à competição entre unidades escolares e professores e a apresentação de iniciativas exitosas como resultantes do esforço próprio de escolas e docentes, que necessitam ser reconhecidas publicamente, enfatizando a meritocracia e a responsabilização.

A análise das iniciativas de premiação, no período analisado, permite verificar que os empresários, por meio de fundações e institutos, têm sido interlocutores privilegiados do governo federal na formulação e realização de programas, ações e projetos pautados em princípios da cultura da avaliação e do desempenho. De acordo com Shiroma et al (2008), a forte participação da iniciativa privada mediante a introdução de incentivos e prêmios oferecidos por fundações e institutos tende a modificar o caráter do ensino público e a "construir um grande consenso, de que os recursos públicos são insuficientes para realizar as tarefas atribuídas à educação neste início de século" (SHIROMA et al, 2008, p. 3), afirmando a necessidade das parcerias com o setor privado. 


\section{Adoção de estratégias de mobilização social para o acompanhamento e fiscalização da qualidade da educação}

A quarta iniciativa do Governo Federal que vem contribuindo para a disseminação da cultura do desempenho na educação básica no país, identificada no presente estudo, consiste na realização de ações de mobilização da sociedade para o acompanhamento e a fiscalização da qualidade da educação.

A mobilização social refere-se às ações desenvolvidas pelo Governo Federal com o objetivo de, por meio de parcerias, impulsionar a sociedade civil para uma nova atitude diante da educação. Nesse cenário, a educação começa a ser delegada a entidades externas ao Estado, principalmente, organizações sociais e institutos e fundações vinculados ao setor empresarial. O apelo constante do Governo Federal, presente nos documentos e programas oficiais, analisados no presente estudo, incentiva o engajamento da sociedade pela educação como proposta para a solução dos problemas da falta da qualidade do ensino, mediante 0 compartilhamento da responsabilidade pelo controle e pela regulação educacional entre Estado e sociedade civil.

No período estudado, destacam-se como iniciativas de mobilização social o Programa "Acorda Brasil - Está na Hora da Escola!", lançado em 1995, no governo do Presidente Fernando Henrique Cardoso, na forma de campanha, e o Plano de Mobilização Social pela Educação (PMSE), lançado em 2008, no governo do Presidente Luiz Inácio Lula da Silva.

Conforme Regina Othon de Lima, coordenadora do programa, o objetivo geral da campanha era "induzir ações em prol de despertar a sociedade para uma nova atitude diante da educação" (LIMA, 2000), no caso específico desse programa, o ensino fundamental. É importante destacar que o programa, não contava com recursos próprios, dessa maneira, as ações eram financiadas pelos segmentos participantes do programa, com destaque, para empresas, sindicatos, instituições, veículos de comunicação, organismos internacionais e artistas (LIMA, 2000). 
As iniciativas de mobilização do programa aconteciam por meio da imprensa do Governo Federal que criou editorias, seções e suplementos especiais sobre a temática da educação, a criação de um canal direto de comunicação entre MEC e a população mediante o serviço 0800616161, graças à parceria com o Itaú e o programa Voz do Brasil, no qual, todas as sextas-feiras durante dois minutos diários, o ministro respondia a cartas dos ouvintes ou esclarecia acerca de algum tipo de programa do MEC. Destaca-se também outras iniciativas, a exemplo, da criação de um Banco de Ações Educacionais, onde eram colocados os registros sobre as ações desenvolvidas no âmbito do programa e que podia ser acessado pela internet e a criação de um site que reúne ideias sobre a educação (LIMA, 2000).

Segundo Aranha (2011), com a criação do Programa Acorda Brasil Está na Hora da Escola!, o Governo Federal "propunha que a sociedade assumisse sua parcela de responsabilidade em relação à qualidade da escola e da educação" (p. 34). Além disso, avalia a referida autora, esse programa "seria muito mais que um programa de mobilização, seria um sentimento participativo cotidiano a habitar cada cidadão" (ARANHA, 2011, p. 34).

O programa demonstra a postura do governo federal brasileiro no momento de reforma do Estado, sob a égide do Plano Diretor (1995), no qual, está posto que para se alcançar a eficiência na administração pública realiza-se a descentralização do poder público com relação às políticas sociais, dentre estas, a educação. Nesse cenário, a educação começa a ser delegada a entidades alheias ao Estado, principalmente, a classe empresarial.

O Plano de Mobilização Social pela Educação (PMSE), criado em 2008, apresenta como foco da mobilização as famílias e a comunidade do entorno das escolas com os mais baixos índices educacionais e os municípios considerados prioritários pelo seu baixo IDEB. Cabe o destaque de que, com o Plano de Mobilização, as famílias e as comunidades são chamadas a 
assumir e compartilhar o dever de fiscalizar, controlar e exigir mudanças no âmbito escolar, de acordo com as diretrizes estabelecidas pelo governo federal, que incentiva a auto-organização de grupos de interesse e o potencial das comunidades na resolução dos seus problemas. Algumas dessas diretrizes, segundo Lima e Martins (2005), são constitutivas do processo de reconfiguração da sociedade civil no contexto de desenvolvimento do neoliberalismo de Terceira Via.

\section{CONSIDERAÇÕES FINAIS}

Ao analisarmos as reformas educacionais, a partir dos anos finais do século XX, é importante considerar que os processos de reestruturação do capital e do Estado capitalista interferiram na educação e geraram desdobramentos. Sob a égide da ideologia neoliberal, a nova forma de gestão do Estado, pautada no gerencialismo trouxe consequências para as políticas públicas e, mais especificamente, para o campo educativo. A implantação do modelo gerencial no setor educacional tem levado à adoção de medidas de racionalização, visando maior eficiência, eficácia e foco no desempenho, envolvendo a utilização de políticas de avaliação e de responsabilização dos gestores e docentes.

No Brasil, como resultado dessas reformas, instalou-se uma cultura do desempenho que impõe o modo de organização da iniciativa privada no setor público, ou seja, uma gestão baseada na qualidade total com a cobrança de resultados atrelados à concessão de estímulos simbólicos, materiais e financeiros.

Ao analisar a atuação do governo federal na disseminação da cultura do desempenho, no período de 1995 a 2012, foi possível identificar quatro grupos de estratégias que buscaram a consolidação, na escola e na sociedade, dos valores que sustentam essa cultura e que contribuem para fortalecer uma "nova sociabilidade" burguesa que vem sendo constituída na sociedade capitalista mundializada e que tem na educação escolar, um espaço privilegiado para sua disseminação. As principais iniciativas referem- 
se à instituição de um sistema nacional de avaliação, à realização de olimpíadas científicas, à criação de iniciativas de premiação docente e à implantação de ações de mobilização social.

O estudo permitiu a identificação de dois momentos no processo de implementação do sistema nacional de avaliação. O primeiro refere-se ao período de 1995 a 2006, no qual o uso dos resultados das avaliações apresentou consequências fracas para gestores e professores. Na segunda conjuntura, de 2007 a 2012, as avaliações tiveram aumentado o seu potencial de interferência na escola, visto que os seus resultados passaram a ser usados com consequências fortes para os diretamente envolvidos no processo de ensino (RAVELA, 2003; BONAMINO; SOUSA, 2012).

O aprofundamento da cultura do desempenho na educação básica brasileira é marcado pela passagem de uma cultura da avaliação com consequências brandas para uma cultura da avaliação com alto impacto (BONAMINO; SOUSA, 2012), na qual ocorre o atrelamento dos resultados das avaliações externas ao pagamento de bonificações.

O governo federal, desde então, vem adotando os resultados das avaliações como ferramenta de gestão dos sistemas e das escolas, condicionando a concessão das transferências voluntárias de recursos financeiros à adoção de estratégias e ao alcance das metas estabelecidas pelo poder central. A terceira geração de implementação do sistema brasileiro de avaliação e a utilização dos resultados com forte impacto para os educadores, gestores e instituições escolares vêm se materializando, nas políticas dos governos estaduais e municipais, com base nos resultados do IDEB e/ou a partir da implementação de sistemas próprios de avaliação e da instituição de mecanismos de premiação e punição. Alguns estados e municípios adotam tais medidas por iniciativa própria, outros em decorrência dos mecanismos de indução do Governo Federal, com destaque para o Plano de Metas Compromisso Todos pela Educação (2007).

Na conjuntura analisada, o governo federal consolidou o seu papel de regulador e avaliador da educação com foco no desempenho. No limite do 
pacto federativo brasileiro, essas medidas vêm induzindo os estados e municípios a aderirem aos programas federais com foco no cumprimento das metas previstas para o IDEB, como exposto.

As iniciativas investigadas, nesse estudo, visam a fomentar, no ambiente escolar, a competição como valor a ser incentivado e naturalizado nas relações sociais dentro e fora da escola, contribuindo, assim, para preservar valores fundamentais das relações sociais capitalistas. Nas estratégias do governo federal para a disseminação da cultura do desempenho na educação básica, é evidente a participação dos empresários como parceiros privilegiados na formulação e implantação de políticas educacionais, no período analisado, principalmente do Movimento Todos pela Educação. Como salienta Ball (2004), "estamos assistindo a uma espécie de colapso das fronteiras entre esferas morais à medida que a educação está sendo empurrada para o redemoinho das mercadorias" ( $p$. 1122).

\section{REFERÊNCIAS}

AFONSO, A. J. Avaliação educacional: regulação e emancipação: para uma sociologia das políticas avaliativas contemporâneas. 4. ed. São Paulo: Cortez, 2009.

ARANHA, M. Al. de M. A participação como princípio orientador da política educacional no Brasil. In: LIMA, P. G.; FURTADO, A. C. (org.). Educação brasileira: interfaces e situações recorrentes. Dourados: Ed. UFGD, 2011.

BALL, S. J. Reformar escolas/reformar professores e os terrores da peformatividade. Revista Portuguesa de Educação, 2002, v. 15, n 2, Universidade do Ninho, p. 03-23. Disponível em: <http://redalyc.uaemex.mx/pdf/374/37415201.pdf>. Acesso em: 23 mar. 2017.

BALL, S. J. Performatividade, privatização e o pós-estado de bem estar. Educação \& Sociedade, Campinas, vol. 25, n.89, set./dez. 2004.

$\checkmark$ Profissionalismo, gerencialismo e performatividade. Cadernos de Pesquisa, v. 35, n. 126, p. 539-564, set/dez. 2005. Disponível em: <http://www.scielo.br/pdf/cp/v35n126/a02n126.pdf>. Acesso em: 30 maio 2017. 
BALL, S. J. Performatividades e fabricações na economia educacional: ruma a uma sociedade performativa. Educação \& Realidade, v. 35, n. 2, 2010. Disponível em: <http://seer.ufrgs.br/educacaoerealidade/article/view/15865>. Acesso em: 30 maio 2017.

BONAMINO, A.; SOUZA, S. Z. L. de. Três gerações de avaliação da educação básica no Brasil: interfaces com o currículo da/na escola. Educação \& Pesquisa. São Paulo, v. 38, n.2, p. 373-388, abr. jun., 2012.

BRASIL. Ministério da Ciência e Tecnologia, CNPq. Edital $n^{\circ}$ 17/2002: Olimpíadas Científicas (2002). Disponível em: <http://memoria.cnpq.br/editais/ct/2002/docs/017.pdf>. Acesso em: 8 set. 2017.

FREITAS, D. N. A avaliação da educação básica no Brasil: dimensão normativa, pedagógica e educativa. Campinas, SP: Autores Associados, 2007.

FREITAS, L. C. de. Três teses sobre as reformas empresariais da educação: perdendo a ingenuidade. Cadernos Cedes, Campinas, v. 36, n. 99, p. 137153, maio/ago. 2016.2 Disponível em $<$ http://www.scielo.br/scielo.php?script=sci_arttext\&pid=\$01013262201600020 $0137 \&$ lng=pt\&nrm=iso $>$. Acesso em: 26 set. 2017.

FREITAS, L. C. Responsabilização, meritocracia e privatização: conseguiremos escapar ao neotecnicismo? In: Seminário de Educação Brasileira (SBE). Campinas, SP, 2011. In: Anais Eletrônicos. Campinas, Centro de Estudos Educação \& Sociedade, 2011. Disponível em: <http://www.cedes.unicamp.br/seminario3/luiz_freitas.pdf>. Acesso em: 30 jun. 2017.

FREITAS, L. C. Os reformadores empresariais da educação: da desmoralização do magistério à destruição do sistema público de educação. Educação \& Sociedade, Campinas: CEDES, v. 33, n.119, p. 353377, abr./jun. 2012.

FREITAS, L. C. Políticas de responsabilização: entre a falta de evidência e de ética. Caderno de Pesquisa. São Paulo, v. 43, n. 148, jan./abr. $2013 a$. Disponível em: <http://www.scielo.br/pdf/cp/v43n148/18.pdf>. Acesso em: 7 out. 2016.

FREITAS, L. C. Caminhos da avaliação de sistemas educacionais no Brasil: o embate entre a cultura da auditoria e a cultura da avaliação. In: BAUER, A. GATTI, B A. (orgs.). Vinte e cinco anos de avaliação de sistemas educacionais no Brasil: implicações nas redes de ensino, no currículo e na formação de professores. Florianópolis: Insular, 2013b, p. 147-173.

LIMA, K. R. de S.; MARTINS, A. S. Pressupostos, princípios e estratégias. In: NEVES, L. M. W. (org.). A nova pedagogia da hegemonia: estratégias do capital para educar para o consenso. São Paulo: Xamã, 2005. 
LIMA, L. C. Reformas da educação pública: democratização, modernização, neoliberalismo. Edições Afrontamento, 2002.

LIRA, P. R. de B. A atuação do governo federal na disseminação da cultura do desempenho na educação básica brasileira (1995-2012). 2013. 223 f. Dissertação (Mestrado em Educação) - Universidade Federal da Paraíba, João Pessoa, 2013.

MARTINS, A. S. A direita para o social: a educação da sociabilidade no Brasil contemporâneo. Juiz de Fora: UFJF, 2009, p. 59-110.

MARTINS, A. M. S.; NEVES, L. M. W. Materialismo histórico, cultura e educação: Gramsci, Thompson e Willians. Revista HISTEDBR On line, Campinas, $n^{\circ} 51, p$. 341-359, jun. 2013.

NOSELLA, P. A atual política para educação no Brasil: a escola e a cultura do desempenho. Revista Faz Ciência, Paraná, v. 12, n. 16, p. 37-56, jul./dez. 2010.

NOSELLA, P.; BUFFA, E.; LEAL, L.L.L. Cultura do desempenho. In: OLIVEIRA, D.A.; DUARTE, A.M.C.; VIEIRA, L.M.F. DICIONÁRIO: trabalho, profissão e condição docente. Belo Horizonte: UFMG/Faculdade de Educação, 2010. CDROM

RAVELA, P. Como os sistemas nacionais de avaliação educativa da América Latina apresentam seus resultados. Programa de Promoção da Reforma Educativa na América Latina e Caribe, Santiago no Chile, maio de 2003. (Série Preal Documentos, 22).

REZENDE, F.; OSTERMANN, F. Olimpíadas de ciências: uma prática em questão. Ciência \& Educação. Bauru, v. 18, n. 1, 2012. Disponível em: <http://www.scielo.br/scielo.php?pid=\$15163132012000100015\&script=sci_abs tract\&tlng=pt>. Acesso em: 10 set. 2017.

SANTOS, L. L. A avaliação em debate. In: BAUER, Adriana; GATTI, Bernadete A. Vinte e cinco anos de avaliação de sistemas educacionais no Brasil: implicações nas redes de ensino, no currículo e na formação de professores. v. 2, Florianópolis: Insular 2013. p. 229-245.

SANTOS, L. L. Formação de professores na cultura do desempenho. Educação \& Sociedade, Campinas, v. 25, n. 89, p. 1145-1157, set./dez. 2004.

SCHNEIDER, P. M.; NARDI, E. L.; DURLI, Z. O PDE e as metas do PAR para a formação de professores da educação básica. Ensaio: avaliação e políticas públicas em educação. Rio de Janeiro, v. 20, n. 75, p. 303-324, abr./jun. 2012. Disponível em: <http://www.scielo.br/scielo.php?pid=S010440362012000200005\&script=sci_arttext>. Acesso em: 2 set. 2016.

SHIROMA, E. O. EVANGELISTA, O. A mística da profissionalização docente. Revista Portuguesa da Educação, Braga, v. 16, n. 2, 2003.

SILVA, A. F. da. Plano de Desenvolvimento da Educação (PDE), avaliação da educação básica e desempenho docente. Jornal de Políticas Educacionais. Curitiba, v. 4, n. 8, p. 63-73, jun./dez. 2010. Disponível em: < http://revistas.ufpr.br/jpe/article/view/21832/14287>. Acesso em: 5 set. 2017. 
SOUSA, S. Z. L. de. Avaliação e gestão da educação básica no Brasil: da competição aos incentivos. In: DOURADO, L. F. (org.). Políticas e gestão da educação no Brasil: novos marcos regulatórios. São Paulo: Xamã, 2009.

Recebido em: Maio de 2017 Aprovado em: Outubro de 2017 